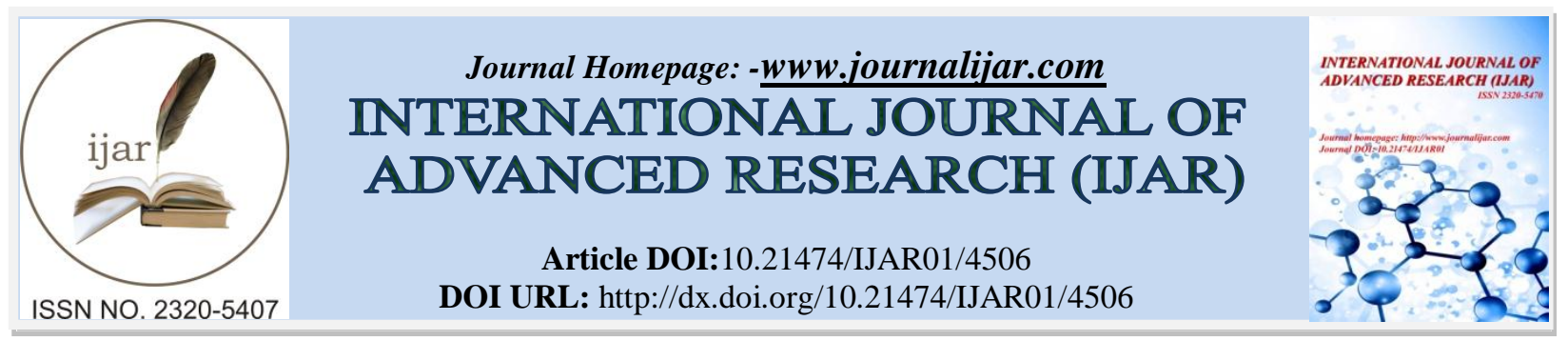

RESEARCH ARTICLE

\title{
DETERMINATION OF PRODUCT LIFE CYCLE THROUGH THE SELECTION OF BEST GEAR MATERIAL BY THE TECHNIQUE FOR ORDER PREFERENCE BY SIMILARITY TO IDEAL SOLUTION.
}

Prithwiraj Jana.

\section{Manuscript Info}

Manuscript History

Received: 17 April 2017

Final Accepted: 19 May 2017

Published: June 2017

Key words:-

Selection parameters, Life cycle,fatigue life,decision making, Cost, Lead Time

\begin{abstract}
Materials and process selection are key issues in optimal design of industrial products. Substituting and selecting materials for different machining parts is relatively common and often. Material selection is a difficult and subtle task, due to the immense number of different available materials. From this point of view paper deal with a set of major gear design criteria which are used for gear material selection. The paper introduces the decision models for best selective material processes. These models are explored in terms of fatigue theory as well as product life cycle is explained and their optimization problems are discussed analytically. The fatigue life of product merged on the best selection of material for better product development, considering economic aspect of present situation. In this book, the writer dives deeper into optimization technique to find out product life.
\end{abstract}

Copy Right, IJAR, 2017,. All rights reserved.

Overview of gear material:-

Gears are commonly made of cast iron, steel, bronze, phenolic resins, acetal, nylon or other plastics. The selection of material depends on the type of loading and speed of operation, wear life, reliability and application. Cast iron is the least expensive. ASTM / AGMA grade 20 is widely used. Grades 30, 40, 50, 60 are progressively stronger and more expensive. CI gears have greater surface fatigue strength than bending fatigue strength. Better damping properties enable them to run quietly than steel.

Nodular cast iron gears have higher bending strength together with good surface durability. These gears are now a days used in automobile cam shafts. A good combination is often a steel pinion mated against cast iron gear. Steel finds many applications since it combines both high strength and low cost. Plain carbon and alloy steel usage is quite common.

Through hardened plain carbon steel with $0.35-0.6 \% \mathrm{C}$ are used when gears need hardness more than 250 to 350 Bhn. These gears need grinding to overcome heat treatment distortion. When compactness, high impact strength and durability are needed as in automotive and mobile applications, alloy steels are used. These gears are surface or case-hardened by flame hardening, induction hardening, nitriding or case carburizing processes. Steels such as En 353, En36, En24, 17CrNiMo6 widely used for gears.

Bronzes are used when corrosion resistance, low friction and wear under high sliding velocity is needed as in wormgear applications. AGMA recommends Tin bronzes containing small \% of $\mathrm{Ni}, \mathrm{Pb}$ or $\mathrm{Zn}$. The hardness may range from 70 to $85 \mathrm{Bhn}$.Non metallic gears made of phenolic resin, acetal, nylon and other plastics are used for light load 
lubrication free quiet operation at reasonable cost. Mating gear in many such applications is made with steel. In order to accommodate high thermal expansion, plastic gears must have higher backlash and undergo stringent prototype testing.

\section{Gear material selection models:-}

Optimal design of gears requires the consideration of the two type parameters:Material and geometrical parameters. The choice of stronger material parameters may allow the choice of finer geometrical parameters and vice versa. Very important difference among these two parameters is that the geometrical parameters are often varied independently. On the other hand, material parameters can be inherently correlated to each other and may not be varied independently. An example of which being the variation of the bending fatigue limit (Sbf) with the core hardness (HB) for some steel materials. If these parameters would be varied independently in an optimization case, it may result in infeasible solutions. Therefore, the final choice of material may not be possible within available data base.If gear material and geometrical parameters are optimized simultaneously then it is common to assume empirical formulas approximating a relation between material parameters for example the bending fatigue limit (Sbf) and ultimate tensile strength (UTS) as a function of hardness. If the choice of material is limited to a list of pre-defined candidates, then two difficulties can be appeared. First, a discrete optimization process should be followed against material parameters. Second, properties of different alternatives materials may not indicate any obvious correlation in the given list. The main goal is to choose material with best characteristic among alternatives.

Table 1. Shows suggested nine materials with their characteristics in a gear material selection .

\section{Research Agenda:-}

In an industry, design is a field that generally deals with different practices of design parameters; the research and development of processes, machine and equipment. The materials and process selection are key issues in optimal design of industrial products. Substituting and selecting materials for different machining parts is relatively common and often. Material selection is a difficult and subtle task, due to the immense number of different available materials. From this point of view paper deal with a set of major gear design criteria which are used for gear material selection. The main gear design criteria are: surface fatigue limit index, bending fatigue limit index, Surface Hardness, Core Hardness, Ultimate tensile strength,Cost,supply Lead Time. Using computer allows a large amount of information to be treated rapidly. One the most suitable models, for ranking alternatives gear materials, are SAW, MOORA, TOPSIS which using a multiple criteria, which all material performance indices and their uncertainties are accounted for simultaneously.

Industrial engineering is a branch of engineering dealing with the optimization of complex processes or systems. It is concerned with the development, improvement, implementation and evaluation of integrated systems of people, money, knowledge, information, equipment, energy, materials, analysis and synthesis, as well as the mathematical, physical and social sciences together with the principles and methods of engineering design to specify, forecast, and evaluate the results to be obtained from such systems or processes.

This paper concerns about increment the decision of material selection of gear manufacturing process and improvement the machinability, accuracy, quality, optimize the cost and time with the industrial view. Overall improvement of optimal design of a gear in manufacturing process considering the fatigue life and other aspect of materials.

\section{Overview of MCDM:-}

Multiple criteria decision making (MCDM) is the process of selecting the best alternative from a set of feasible alternatives considering multiple conflicting criteria. In precise terms criteria are considered to be 'strictly' conflicting if the increase in satisfaction of one results in a decrease in satisfaction of the other. An MCDM process always contains at least two alternatives and two conflicting criteria (Bhattacharya et al., 2003). MCDM are divided two broad categories: Multiple Attribute Decision Making (MADM) and Multiple Objective Decision Making (MODM). Several useful tools for solving of MCDM problems are,

* Simple Additive Weighting method (SAW)

* Technique for Order Preference by Similarity to Ideal Solution (TOPSIS)

* Multi Objective Optimization Ratio Analysis(MOORA)

* Analytical Hierarchy Method (AHP)

* Analytical Network Method (ANP) etc. 
Technique for order preference by similarity to ideal solution (TOPSIS):-

TOPSIS is an evaluation method that is often used to solve MCDM problems. It has a number of applications in practice, such as comparison of company performances, financial ratio performance within a specific industry and financial investment in advanced manufacturing systems, etc. However, there are also some limits to it. So far, the work on how to improve original TOPSIS method has mainly emphasized on improving the weight to sensitize the $\mathrm{R}$ value $[6,7]$. Besides, there has also been improvement on formula of the $\mathrm{R}$ value, such as the 'Miqiezhi' method [8]. Because of the complexity of evaluation problems, a better and simpler method is required to understand the inherent relationship between the R value and alternative evaluation. In this report, a novel, modified TOPSIS (MTOPSIS) method is described as a process of calculating the distance between the alternatives and the reference points in the $\mathrm{D}+\mathrm{D}^{-}$-plane and constructing the $\mathrm{R}$ value to evaluate quality of alternative.

\section{Entropy:-}

Entropy was originally a thermodynamic concept, first introduced into information theory by Shannon (see Shannon, 1948 [21]). It has been widely used in the engineering, socioeconomic and other fields. According to the basic principles of information theory, information is a measure of system's ordered degree, and the entropy is a measure of system's disorder degree.

\section{Overview of MATLAB:-}

MATLAB is a high-performance language for technical computing. It integrates computation, visualization, and programming in an easy-to-use environment where problems and solutions are expressed in familiar mathematical notation. Typical uses include:

- Math and computation

- Algorithm development

- Modeling, simulation, and prototyping

- Data analysis, exploration, and visualization

- Scientific and engineering graphics

- Application development, including graphical user interface building

MATLAB is an interactive system whose basic data element is an array that does not require dimensioning. This allows you to solve many technical computing problems, especially those with matrix and vector formulations, in a fraction of the time it would take to write a program in a scalar non interactive language such as C or Fortran.

The name MATLAB stands for matrix laboratory. MATLAB was originally written to provide easy access to matrix software developed by the LINPACK and EISPACK projects. Today, MATLAB uses software developed by the LAPACK and ARPACK projects, which together represent the state-of-the-art in software for matrix computation.

MATLAB features a family of application-specific solutions called toolboxes. Very important to most users of MATLAB, toolboxes allow you to learn and apply specialized technology. Toolboxes are comprehensive collections of MATLAB functions (M-files) that extend the MATLAB environment to solve particular classes of problems. Areas in which toolboxes are available include signal processing, control systems, neural networks, fuzzy logic, wavelets, simulation, and many others.

\section{Objective of work:-}

3.1The proposed research work is planned into 5 stages:

3.1.1 Identification of problem and setting up objective.

3.1.2 Analysis of parameter and design of optimization tool.

3.1.3 Effective simulation using MATLAB.

3.1.4 Find fatigue life by construction of S-N diagram

3.1.5 With the help of optimization tool rank the best alternatives (materials).

\section{Phase 1:-}

Different objectives would be chosen form literature review for analysis and improvement, such as various alternative of gear materials and their criteria. Formation of MATRIX of gear materials to improve machinability, accuracy, quality, optimize the cost and time with the industrial view of a gear for better manufacturing product. 
Phase 2:-

Design is considered with proper selection of tool. For this research work MCDM is preferred as an optimization tool. But since the various method of MCDM is heavily used in material selection problem solving, hence might be some possible effective method can be added in this paper. In this stage more objective and harder matrix will be taken together.

A model of the proposed technique is presented below as flow diagram. This technique is a multiple criteria based decision making optimization technique which is mainly based on ranking to solve the problem and indicate the best selection of gear material.

Phase 3:

In this paper the problem solved by the MATLAB and showing the graph of materials and also detect the accuracy of the following problem.

Phase 4:

Find fatigue life by construction of S-N diagram

Phase 5:

With the help of optimization tool (SAW, MOORA \& TOPSIS) rank the best alternatives (materials), by MATLAB software.

Selection of Gear Materials Considering Technical Economic and Supply Aspect by Ranking in MATLAB problem definition:-

An organization has got 03 different materials with different specifications for gear. The decision maker considered 7 selection criteria. The materials are as follows:

\begin{tabular}{|c|c|c|c|c|c|c|c|c|}
\hline MATERIAL & Grade & $\begin{array}{l}\text { Surface } \\
\text { (Bhn) } \\
\text { Hardness } \\
\text { (C1) } \\
\end{array}$ & $\begin{array}{l}\text { Core } \\
\text { (Bhn) } \\
\text { Hardness } \\
\text { (C2) } \\
\end{array}$ & $\begin{array}{l}\text { Surface } \\
\text { Fatigue } \\
\text { Limit } \\
\text { (MPa) } \\
\text { (C3) } \\
\end{array}$ & $\begin{array}{l}\text { Bending } \\
\text { Fatigue } \\
\text { Limit } \\
\text { (MPa) } \\
\text { (C4) }\end{array}$ & $\begin{array}{l}\text { UTS } \\
\text { (MPa) }\end{array}$ & 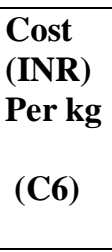 & $\begin{array}{l}\text { Supply } \\
\text { Lead } \\
\text { Time } \\
\text { (In } \\
\text { week) } \\
\text { (C7) } \\
\end{array}$ \\
\hline $\begin{array}{l}\text { Surface } \\
\text { Hardened } \\
\text { Alloy Steel } \\
\text { (M6) }\end{array}$ & $\begin{array}{l}\text { SAE } \\
8620\end{array}$ & 542 & 229 & 1160 & 680 & 1850 & 60 & 6 \\
\hline $\begin{array}{l}\text { Carburised } \\
\text { steel } \\
\text { (M7) }\end{array}$ & $\begin{array}{l}\text { SAE } \\
8620\end{array}$ & 647 & 297 & 1500 & 920 & 2300 & 60 & 5 \\
\hline $\begin{array}{l}\text { Nitrided steel } \\
\text { (M8) }\end{array}$ & EN40B & 693 & 297 & 1250 & 760 & 1250 & 72 & 5 \\
\hline
\end{tabular}

\section{Table:01}

Determination of Fatigue life of Three Best Gear Materials Considering Technical Aspect:calculating the fatigue life of three best materials:-

* Gear teeth act as a cantilever beam and it undergoes a fluctuating load so the bending fatigue limit is considerable.

* Manufacturing of gears undergoes a heat treatment process which is case hardening so surface fatigue limit of those materials are not to be considerable.

* For ferrous materials like steel, S-N curve becomes asymptotic at $10^{6}$ cycles, which indicates the stress amplitude corresponding to infinite number of stress cycles. The magnitude of this stress amplitude at $10^{6}$ cycles represents the endurance limit of the materials.

* Considerable load of this experiment is $1000 \mathrm{MPa}$.

* Carburised Steel (M7) 


\section{Construction of s-n diagram}

$\begin{array}{lll}\checkmark & \sigma_{\mathrm{ut}}(\mathrm{MPA}) & =2300 \\ \checkmark & 0.9 \sigma_{\mathrm{ut}} & =2070 \\ \checkmark & \log 10\left(0.9 \sigma_{\mathrm{ut}}\right) & =3.31 \\ \checkmark & \sigma_{\mathrm{e}} & =920 \\ \checkmark & \log 10\left(\sigma_{\mathrm{e}}\right) & =2.96 \\ \checkmark & \operatorname{Load} & =1000 \mathrm{MPa}\end{array}$

Calculation number of cycle

$$
\begin{aligned}
\mathrm{EF}=\frac{D B \times A E}{A D}=\frac{(6-3) \times(3.31-3)}{(3.31-2.96)} \\
=\frac{0.93}{0.35}=2.66 \\
\log _{10} \mathrm{~N}=3+\mathrm{EF} \\
=3+2.66=5.66 \\
\mathrm{~N}=457008 \text { CYCLE }
\end{aligned}
$$

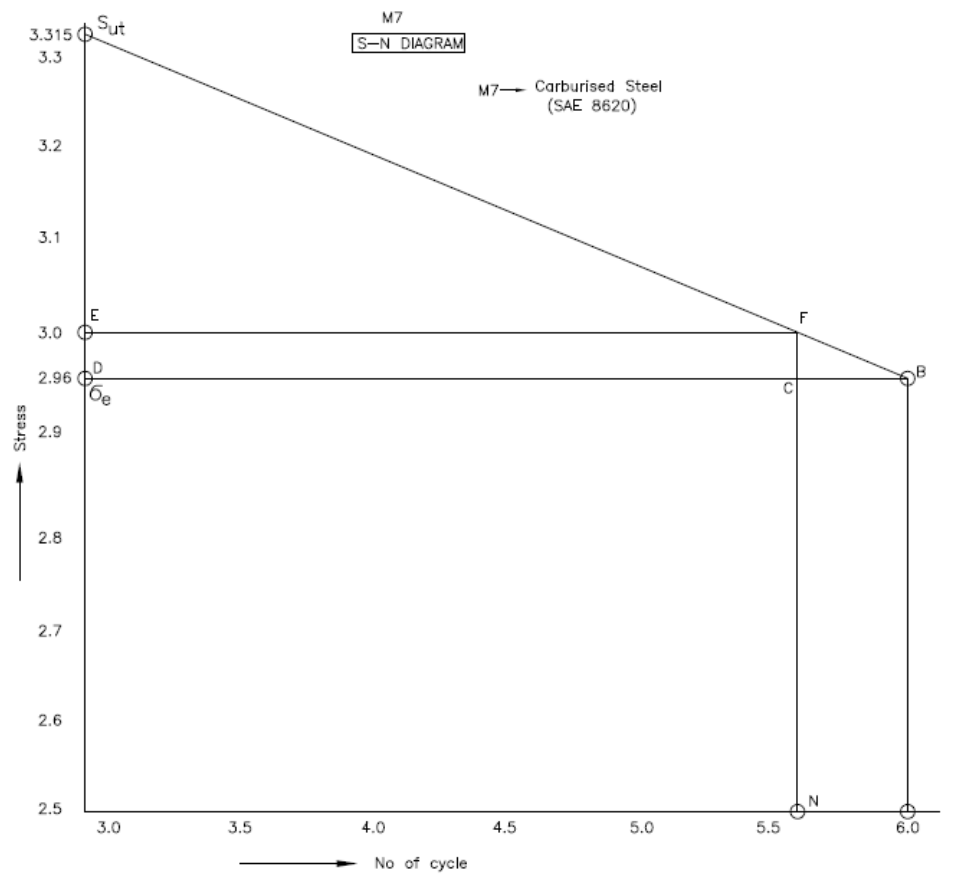

Nitrided Steel (M8)

Fig:01

\section{Construction of s-n diagram}

$$
\begin{array}{lll}
\checkmark & \sigma_{\mathrm{ut}}(\mathrm{MPA}) & =1250 \\
\checkmark & 0.9 \sigma_{\mathrm{ut}} & =1125 \\
\checkmark & \log 10\left(0.9 \sigma_{\mathrm{ut}}\right)=3.05 \\
\checkmark & \sigma_{\mathrm{e}} & =760 \\
\checkmark & \log 10\left(\sigma_{\mathrm{e}}\right) & =2.88 \\
\checkmark & \operatorname{LOAD} & =1000 \mathrm{Mpa}
\end{array}
$$

\section{Calculation number of cycle}

$$
\begin{gathered}
\begin{aligned}
\mathrm{EF}=\frac{D B \times A E}{A D}=\frac{(6-3) \times(3.05-3)}{(3.05-2.88)} \\
=\frac{0.15}{0.17}=0.88
\end{aligned} \\
\begin{array}{c}
\log _{10} \mathrm{~N}=3+\mathrm{EF} \\
=3+0.88=3.88
\end{array} \\
\begin{aligned}
\mathrm{N}=7585 \mathrm{CYCLE}
\end{aligned}
\end{gathered}
$$




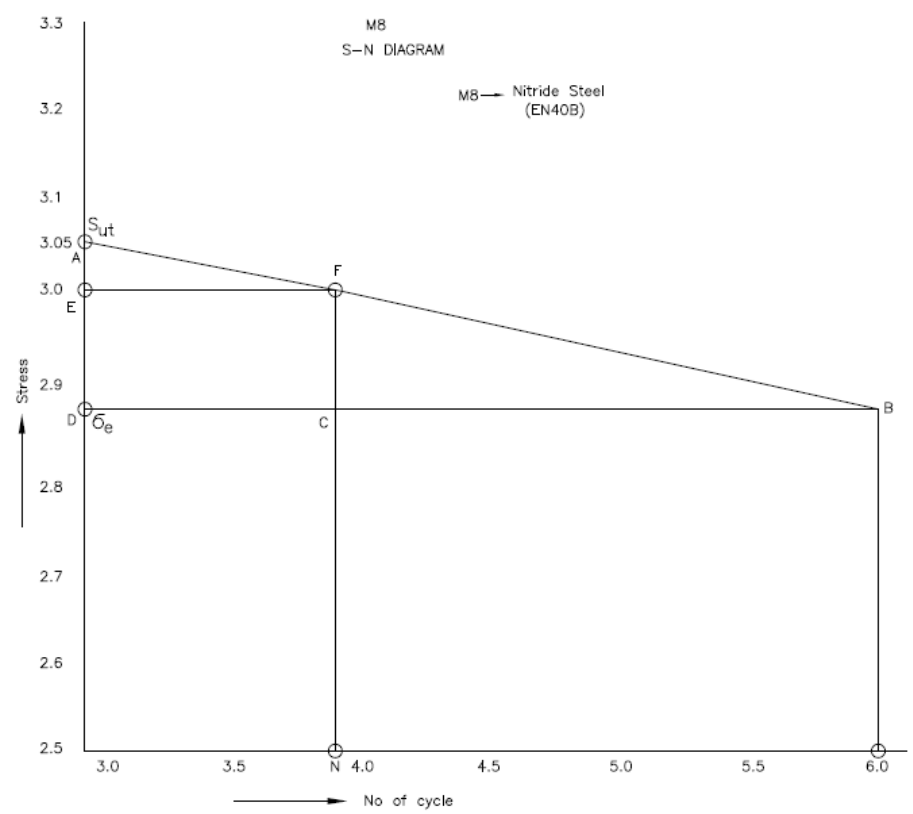

Fig:02

* Surface Hardened Alloy Steel (M6)

Construction of s-n diagram

$\begin{array}{lll}\checkmark & \sigma_{\text {ut }}(\text { MPA }) & =1850 \\ \checkmark & 0.9 \sigma_{\text {ut }} & =1665 \\ \checkmark & \log 10\left(0.9 \sigma_{\text {ut }}\right)= & =3.22 \\ \checkmark & \sigma_{\mathrm{e}} & =680 \\ \checkmark & \log 10\left(\sigma_{\mathrm{e}}\right) & =2.83 \\ \checkmark & \operatorname{LOAD} & =1000 \mathrm{MPa}\end{array}$

Calculation number of cycle

$$
\begin{gathered}
\begin{aligned}
\mathrm{EF}=\frac{D B \times A E}{A D}=\frac{(6-3) \times(3.22-3)}{(3.22-2.83)} \\
=\frac{0.66}{0.39}=1.69
\end{aligned} \\
\begin{aligned}
\log _{10} \mathrm{~N} & =3+\mathrm{EF} \\
= & 3+1.69=4.69
\end{aligned} \\
\mathrm{~N}=489775 \mathrm{CYCLE}
\end{gathered}
$$




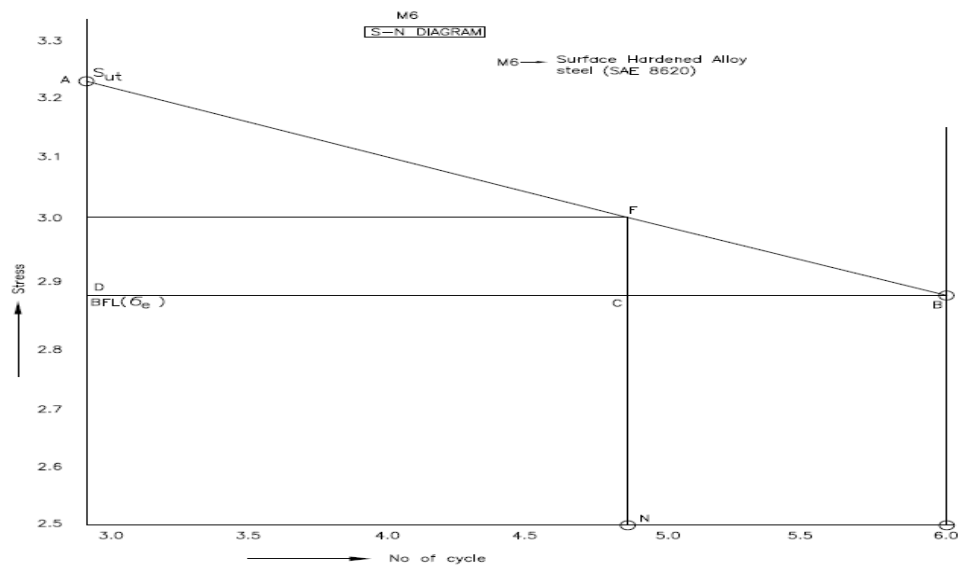

Fig:03

Comparative analysis on number of cycle of gear materials using s-n diagram:

\begin{tabular}{|l|l|l|}
\hline MATERIAL & RANK & NO. OF CYCLE \\
\hline $\begin{array}{l}\text { Carburised Steel } \\
\text { (M7) }\end{array}$ & 1 & 457008 CYCLE \\
\hline $\begin{array}{l}\text { Nitrided Steel } \\
\text { (M8) }\end{array}$ & 2 & 7585 CYCLE \\
\hline $\begin{array}{l}\text { Surface Hardened Alloy Steel } \\
\text { (M6) }\end{array}$ & 3 & 489775 CYCLE \\
\hline
\end{tabular}

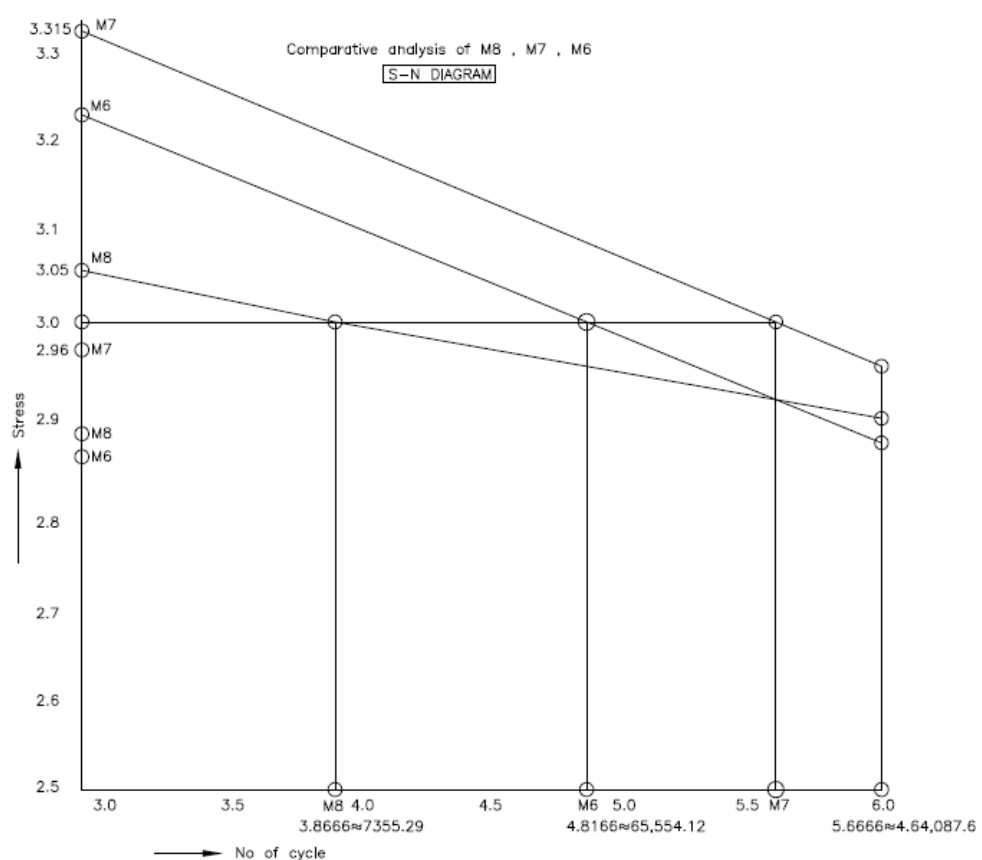

Fig:04

Selection of best material:-

Formation of developed matrix 


\begin{tabular}{|c|c|c|c|c|c|c|c|c|c|}
\hline MATERIAL & Grade & $\begin{array}{l}\text { Surface } \\
\text { (Bhn) } \\
\text { Hardness } \\
\text { (C1) }\end{array}$ & $\begin{array}{l}\begin{array}{l}\text { Core } \\
\text { (Bhn) }\end{array} \\
\text { Hardness } \\
\text { (C2) }\end{array}$ & $\begin{array}{l}\text { Surface } \\
\text { Fatigue } \\
\text { Limit } \\
\text { (MPa) } \\
\text { (C3) }\end{array}$ & $\begin{array}{l}\text { Bending } \\
\text { Fatigue } \\
\text { Limit } \\
\text { (MPa) } \\
\text { (C4) }\end{array}$ & $\begin{array}{l}\text { UTS } \\
\text { (MPa) }\end{array}$ & $\begin{array}{l}\text { Cost } \\
\text { (INR) } \\
\text { Per } \\
\text { kg } \\
\text { (C6) }\end{array}$ & $\begin{array}{l}\text { Supply } \\
\text { Lead } \\
\text { Time } \\
\text { (In } \\
\text { week) } \\
\text { (C7) }\end{array}$ & $\begin{array}{l}\text { Number of } \\
\text { cycles }\end{array}$ \\
\hline $\begin{array}{l}\text { Surface } \\
\text { Hardened } \\
\text { Alloy Steel } \\
\text { (M6) }\end{array}$ & $\begin{array}{l}\text { SAE } \\
8620\end{array}$ & 542 & 229 & 1160 & 680 & 1850 & 60 & 6 & $\begin{array}{l}489775 \\
\text { CYCLE }\end{array}$ \\
\hline $\begin{array}{l}\text { Carburised } \\
\text { steel } \\
\text { (M7) }\end{array}$ & $\begin{array}{l}\text { SAE } \\
8620\end{array}$ & 647 & 297 & 1500 & 920 & 2300 & 60 & 5 & $\begin{array}{l}457008 \\
\text { CYCLE }\end{array}$ \\
\hline $\begin{array}{l}\text { Nitrided } \\
\text { steel } \\
\text { (M8) }\end{array}$ & EN40B & 693 & 297 & 1250 & 760 & 1250 & 72 & 5 & $\begin{array}{l}7585 \\
\text { CYCLE }\end{array}$ \\
\hline
\end{tabular}

Table-02

Topsis method by using matlab:

\section{RESULT:}

The weighted values are:

$$
\begin{array}{llllllll}
0.1059 & 0.1080 & 0.1089 & 0.1100 & 0.1149 & 0.1022 & 0.1001 & 0.2501
\end{array}
$$

The weighted values got from entropy method

STEP1: Determination of normalized decision matrix

$\begin{array}{llllllll}0.7821 & 0.7710 & 0.7733 & 0.7391 & 0.8043 & 0.8333 & 0.8333 & 0.1122 \\ 0.9336 & 1.0000 & 1.0000 & 1.0000 & 1.0000 & 0.8333 & 1.0000 & 0.0158 \\ 1.0000 & 1.0000 & 0.8333 & 0.8261 & 0.5435 & 1.0000 & 1.0000 & 1.0000\end{array}$

\section{STEP 2:}

Determination of positive ideal solution: taking the maximum values of each column from the normalized decision matrix

$\begin{array}{llllllll}1 & 1 & 1 & 1 & 1 & 1 & 1 & 1\end{array}$

Determination of negetive ideal solution: taking the minimum values of each column from the normalized decision matrix
0.7821
0.7710
0.7733
0.7391
0.5435
0.8333
0.8333
0.0158

\section{STEP 3:}

Calculation of the separation measure from the positive ideal solution(di_Plus)
0.4805
0.4955
0.1740

Calculation of the separation measure from the negetive ideal solution(di_Minus)

0.1007

0.2188

0.5096

STEP 3: Calculation of $\mathrm{R} \_\mathrm{i}$

$\begin{array}{lll}0.1732 & 0.3064 & 0.7454\end{array}$

Arranging the final value in descending order:

M8 > M7 > M6 


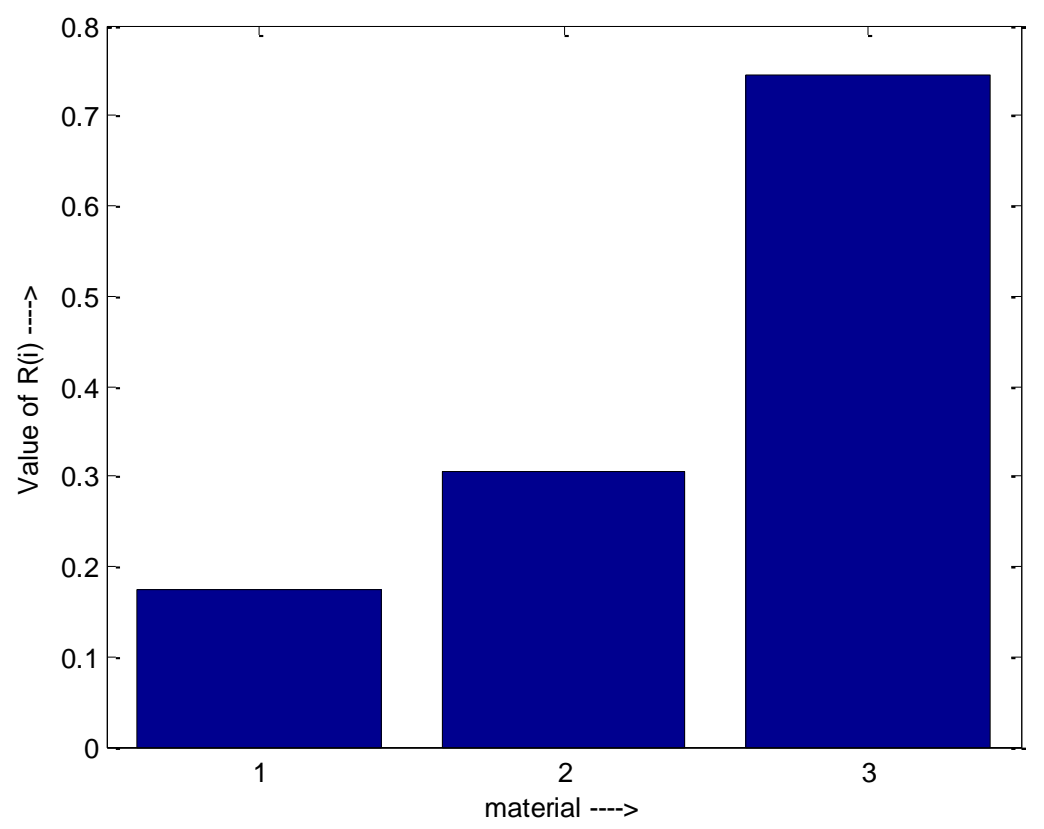

Fig: 05

\section{Conclusion:-}

It is quite clear that selection of a proper Gear Materials for a given manufacturing application involves a large number of considerations. The use of TOPSIS method is observed to be quite capable and computationally easy to evaluate and select the proper material from a given set of alternatives. These methods use the measures of the considered criteria with their relative importance in order to arrive at the final ranking of the alternative Gear Materials. Thus, these popular MCDM methods can be successfully employed for solving any type of decisionmaking problems having any number of criteria and alternatives in the manufacturing domain. Use of MATLAB software makes MCDM problem simple and gives prompt results which is very essential in today's decision making environment.

As far as design is concern fatigue life is very much important factor that influence the overall working life of the machine as well as the performance efficiency throughout its life span.

\section{References:-}

1. Ashby, M.F.: Multi-objective optimization in material design and selection. Acta Mater. 48(1), 359-369

2. Ashby, M.F.: Materials Selection in Mechanical Design. Elsevier, Boston (2005)

3. Collette, Y., Siarry, P.: Multiobjective Optimization. Springer-Verlag, New York (2003)

4. Dehghan-Manshadi, B., Mahmudi, H., Abedian, A., Mahmudi,R.: A novel method for materials selection in mechanical design: Combination of non-linear normalization and a modified digital logic method. Mater. Des. 28(1), 8-15 (2007)

5. Milani, A.S., Shanian, A., Madoliat, R., Nemes, J.A.: The effect of normalization norms in multiple attribute decision making models: a case study in gear material selection.Struct. Multidisciplinary Optim. 29, 312-318 (2005)

6. BRECHT, Y. et al., Challenges in materials and process selection, Progress in materials Science 46 (2001), p. 407-428

7. SHANIAN, A., SAVADOGO, O., A material selection model based on the concept of multiple attribute decision making, Material in Design,27(2006), p. 329-337

8. GLIGORIJEVIĆ R., Materials for gears manufacturing, their dynamic and structuralcharacterisics and heattretment, Journal of terotchnology, V.5, No.6, 1976, p367-379

9. MILANI A., SHANIAN, A., Gear material selection with uncertain and incomplete data,Journal of Mechanics and Material in Design, 3(2006), p. 209- 222

10. JUVINALL, C., MARSHEK,M., Fundamentals of Machine Component Design, Wiley, New. 